\title{
Portrait of the East Midlands
}

\author{
By Jen Beaumont, Office for National Statistics
}

\section{Key points}

The East Midlands region:

- is one of the smaller English regions in terms of the number of residents

- is projected to have higher population growth over the next 25 years than any other English region with particularly high increases in the older age groups

- is expected to have large increases in the stock of dwellings because of projected population increases and additional migration

- had the highest percentage of industrial output and employee jobs in manufacturing and the lowest percentage of output and employee jobs in the financial sector of any region or country in the UK in 2007

- has a relatively low level of deprivation overall but with persistent sub-regional areas of higher deprivation

- has a workforce with a relatively low level of skills compared with the UK as a whole

- has a smaller proportion of residents employed in higher skilled occupations when compared with the national average

- has maintained relatively high levels of employment compared with the UK and English averages even during economic downturns

Jen Beaumont is Regional Statistician for the

East Midlands

Tel: 01159471777

Email: jen.beaumont@ons.gsi.gov.uk

\section{Introduction}

The East Midlands has a diverse landscape, economy and population. There are large rural areas, including areas which attract many visitors such as the Peak District National Park in the north and the Lincolnshire Wolds in the east. There are also large conurbations and other relatively industrialised areas.

The region is bordered by Yorkshire and The Humber, the North West, the West Midlands, the South East and East of England regions and by the North Sea coastline to the east. In area it is 15,600 square $\mathrm{km}$ making it the fourth largest English region, smaller than the South West, East of England and the South East. The region covers 12 per cent of the total area of England and 6 per cent of the UK. It contains five counties; Derbyshire, Leicestershire, Lincolnshire, Northamptonshire and Nottinghamshire, and four unitary authorities: Derby, Leicester, Rutland and Nottingham. There are 36 districts contained within the counties in the region.

The population of the East Midlands in 2007 was estimated to be 4.4 million, 7.2 per cent of the population of the UK. The population of the region is projected to grow at a faster rate than any other English region over the next 25 years, increasing the pressure on housing and jobs. Recent population change and projected population increase is not spread evenly across the region, so the pressure to build houses to meet these population increases and to increase the supply of affordable housing is not uniform. For example, Northamptonshire, which has high projected population growth, is part of the Milton Keynes East Midlands Growth area and there are also a number of other housing growth points in the region.

The higher education establishments in the East Midlands are Bishop Grosseteste University College, Lincoln, the University of Derby, De Montfort University, Leicester University, the University of Lincoln, Loughborough University, the University of Northampton, Nottingham Trent University and Nottingham University, with around 149,000 under graduate and postgraduate students in 2007/08 (6.5 per cent of the total number of students in the UK).

The region, particularly the north and west, is well served by transport links. East Midlands Airport in Leicestershire is situated between the three main cities of Derby, Leicester and Nottingham. There are high-speed trains to London with connections to the West Midlands and the South West. The M1 motorway also serves the three largest conurbations. 


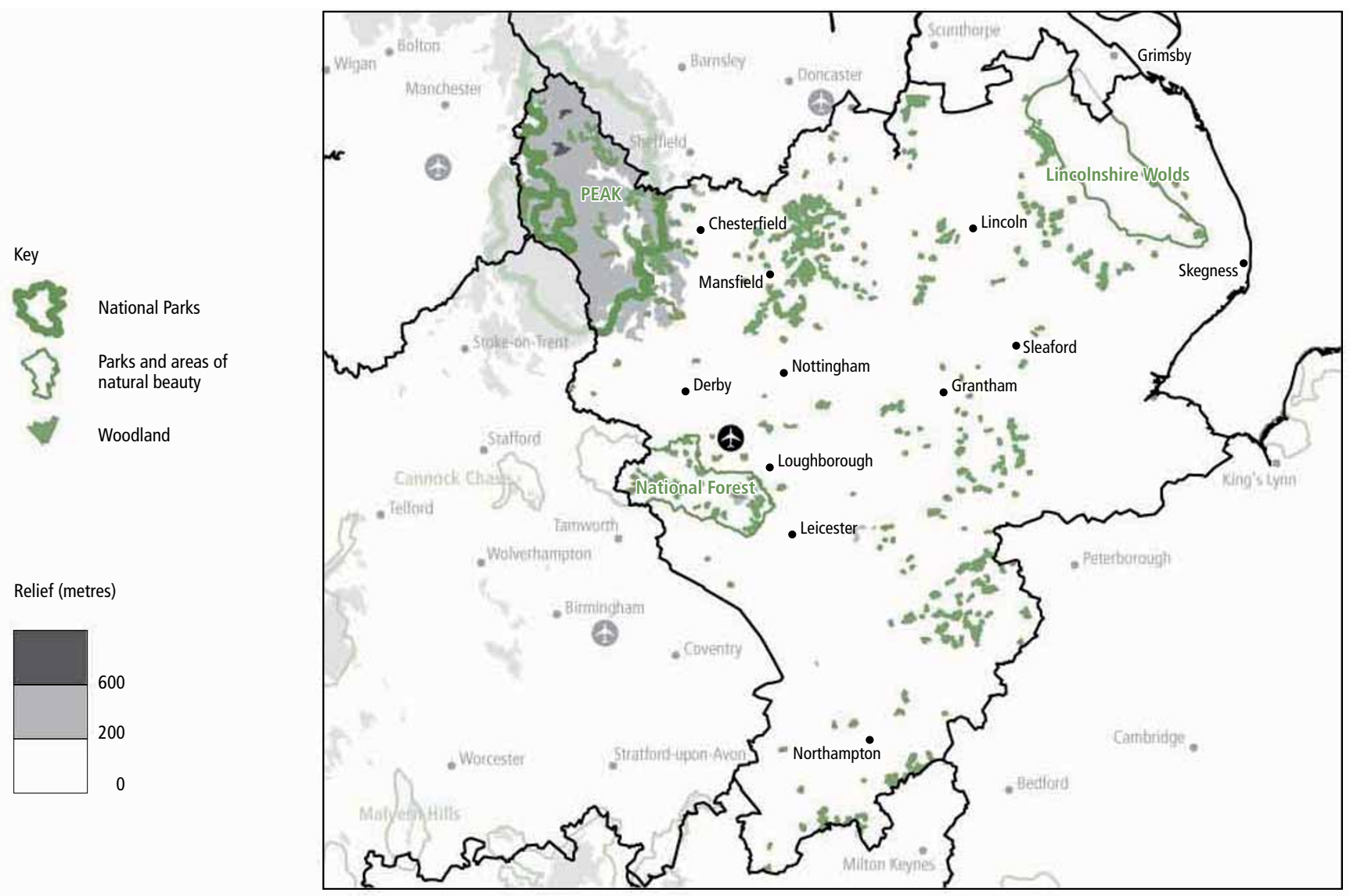

Map 4.2 East Midlands local or unitary authority, NUTS $2^{1}$ sub-regions and Rural and Urban Area Classification ${ }^{2}$

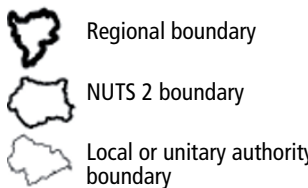

Rural and Urban Area Classification

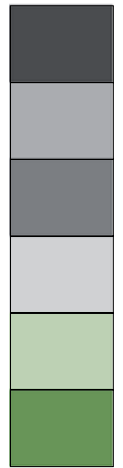

Urban population over 10,000 -Less Sparse

Urban population over 10,000 -Sparse

Town and Fringe-Less Sparse

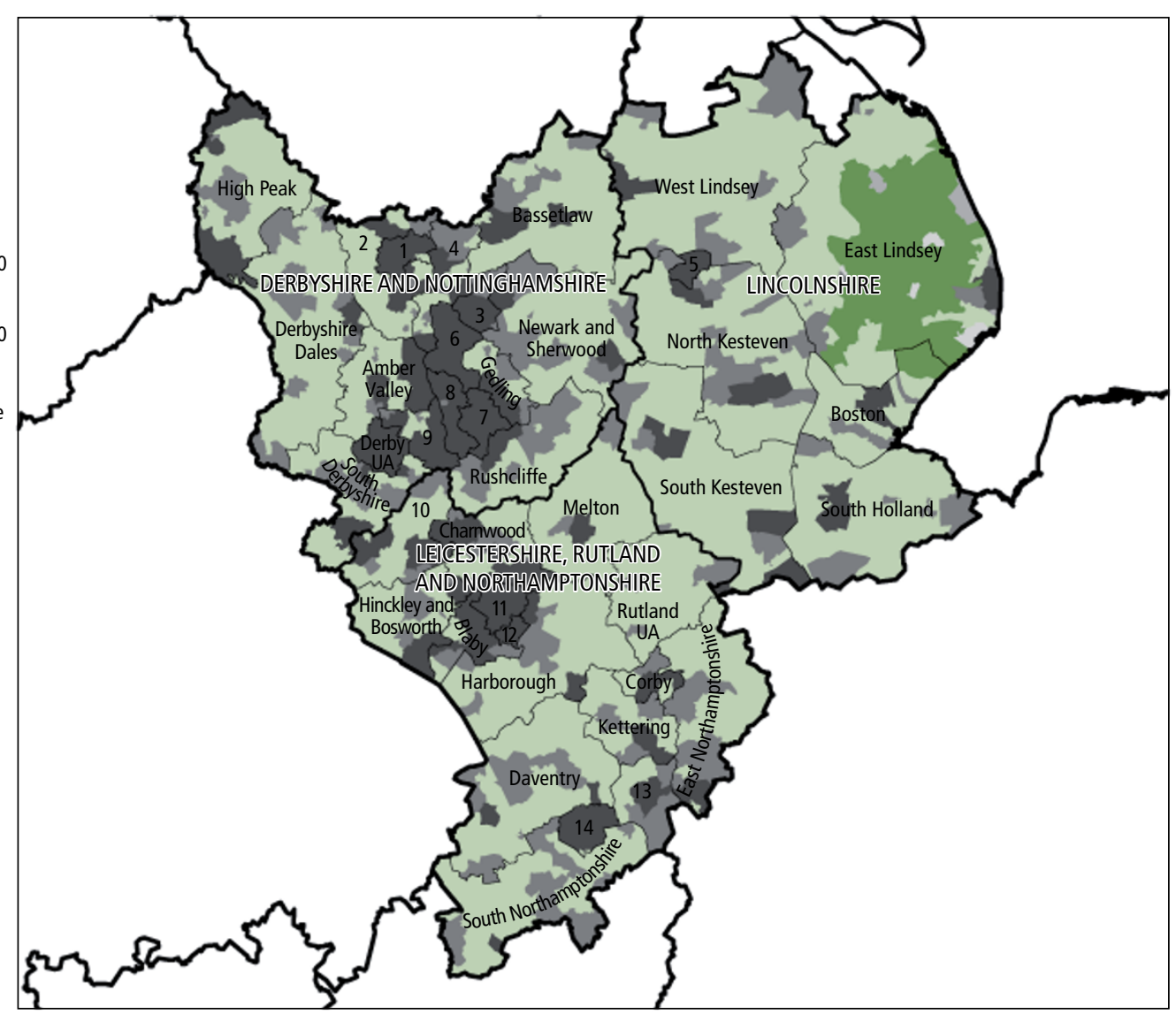

1 Chesterfield

2 North East Derbyshire

3 Mansfield

4 Bolsover

5 Lincoln

6 Ashfield

7 Nottingham UA

8 Broxtowe

9 Erewash

10 North West Leicestershire

11 Leicester UA

12 Oadby and Wigston

13 Wellingborough

14 Northampton

1 Nomenclature of Units for Territorial Statistics, level 2.

2 By Lower Layer Super Output Area. 
When the United Kingdom began to industrialise, the East Midlands developed into a region with a diverse industrial base, including coal mining and the textile industry, which acted as a stabilising factor against the worst of the recession in the early 1990's, although traditional industries such as coal mining and textiles manufacturing have suffered a long-term decline. As the coal industry contracted, the coalfield areas in Derbyshire and Nottinghamshire suffered higher unemployment rates than the rest of the region. Agriculture is more important to the south and east of the region and the East Midlands has the highest proportion of agricultural land of all UK regions.

The manufacturing sector, despite being in decline, still makes the highest contribution to the East Midlands economic output. As a proportion of total regional output, manufacturing is greater in the East Midlands than in any other region or country of the UK. As the economy of the region is more dependent on manufacturing than other regions, a higher proportion of the workforce are in lower skilled occupations. The greatest growth in economic contribution has been in the real estate sector.

In 2007, over 70 per cent of the region's population were estimated to be living in urban areas with a population of over 10,000, with just over 16 per cent resident in smaller towns. About 13 per cent of the population were resident in villages, hamlets and isolated dwellings. (See Map 4.2)

The north west of the region is dominated by the southern part of the Pennines forming the Peak District National Park. (See Map 4.1) This receives 22 million visits each year, almost a third of all visits to national parks in England. In contrast, the south and east of the region is much flatter, characterised by rolling lowlands. The region is also notable for its forests: Sherwood Forest, the legendary home of Robin Hood in Nottinghamshire, and the newly developing National Forest, located predominately in Leicestershire. The landscape is primarily rural, but there are major urban centres in the cities of Derby, Leicester, Lincoln and Nottingham, and the town of Northampton. (See Map 4.2) The region has 392 Sites of Special Scientific Interest (SSSIs), covering an area of 1,650 sq $\mathrm{km}$. Close to 40 per cent is located in the part of the Wash in the East Midlands which is largely marine. The Wash also contains a Special Protection Area (SPA) for its internationally important bird populations. In every county except Derbyshire, less than 2 per cent of the land is designated as terrestrial SSSI.

\section{Population}

In 2007 the East Midlands population was estimated to be 4.4 million, 7.2 per cent of the population of the UK. Of the 12 regions in the UK, the East Midlands region was one of the smallest, only the North East, Wales and Northern Ireland had lower populations. Within the East Midlands there were four local authority areas with populations of over 200,000 in 2007, Derby Unitary Authority (UA), Leicester UA, Northampton Borough Council (BC) and Nottingham UA. These four conurbations account for over 23 per cent of the entire regional population. The local authority area with the smallest population in 2007 was Rutland UA with an estimated 38,400 residents. (Online table 1.2)

In 2007 the region had a population density of 282 people per square km, the lowest for any English region apart from the South West. Population density at local authority district level in the East Midlands ranged from 76 people per square $\mathrm{km}$ in West Lindsey in Lincolnshire, to 3,991 in Leicester UA.

Between 2002 and 2007, the population increased by 178,000 or 4.2 per cent, a much higher increase than the average of 2.9 per cent for England and the highest increase of any of the English regions.

More recently, the population increased by 0.8 per cent between 2006 and 2007. Net migration and other changes accounted for more than 70 per cent of the change between 2006 and 2007 compared with just over half the population growth in the UK as a whole. Of the upper tier authorities in the East Midlands, Northamptonshire County had the largest numerical population change of 9,000 between 2006 and 2007, two thirds because of net migration and other changes (see Figure 4.3). (Online table 10.8)

Figure 4.4 shows the net change per 10,000 residents from inter-regional and international migration by region for 2007. The total inflow is greater than the total outflow for both interregional and international migration in the East Midlands. The net effect of migration was to increase the population in 2007 by about 52 people per 10,000 residents or a net total of 23,000 new residents, of which about two thirds were international migrants. (Online table 10.6)

The 2006 based population projections show that by 2026 the East Midlands is expected to have 5.3 million residents, 21 per cent more than in 2006 and the largest increase of the English

\section{Figure 4.3 Components of population change by county and unitary authority, East Midlands, mid-2006 to mid-2007}

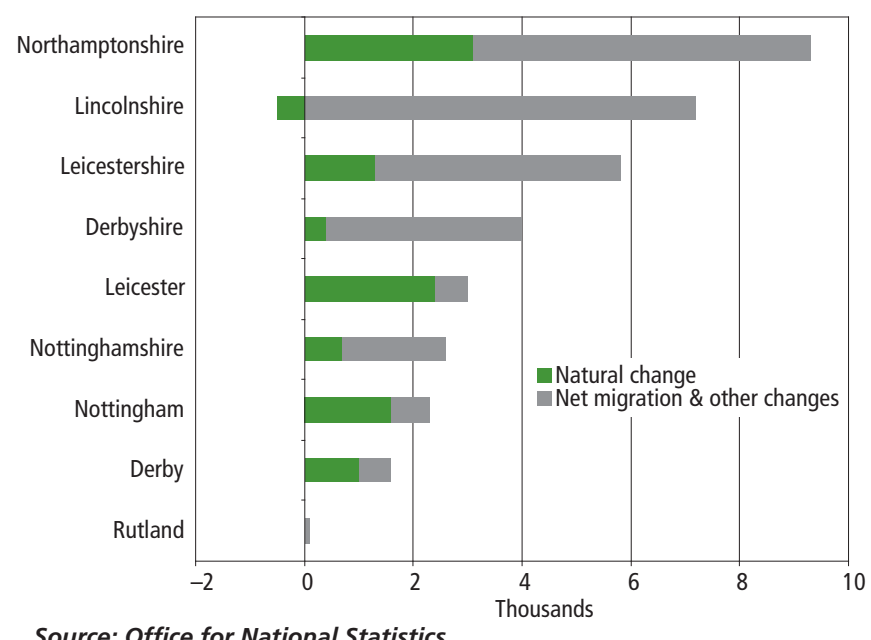


Figure 4.4 Net migration per 10,000 residents, by region, 2007 and a higher increase than that projected for England (46 per cent). There is an even larger projected increase of nearly 80 per cent for residents aged 80 and over compared with 65 per cent in England.

Experimental population estimates by ethnic group for 2006 suggest that 8.6 per cent of the region's residents were nonWhite. Those that classed themselves as White amounted to 91 per cent of residents, compared with 89 per cent in England as a whole. Only the West Midlands (87 per cent) and London (69 per cent) had lower percentages of White residents. The largest ethnic group within the non-White category in the region were Asian or Asian British who made up 4.8 per cent of the population. (Online table 10.4)

An estimated 92 per cent of people who were usually resident in the East Midlands in 2008 were born in the UK, higher than the UK average. This has decreased since 2004 in both the UK as a whole and the East Midlands. UK-born residents range from 96 per cent in the North East to 67 per cent in London. The percentage of UK-born residents at upper tier authority level in the East Midlands in 2008 varies considerably, from 71 per cent in Leicester UA to 97 per cent in Derbyshire County.

\section{Households and housing}

There were approximately 1.8 million households in the East Midlands in 2006, 10 per cent of the total in England. (Online table 10.15) The region had the lowest percentage of single person households (30 per cent) compared with other English regions.

There are projected to be around 2.4 million households in the East Midlands by 2026, a rise of over 30 per cent from 2006. (Figure 4.6 and Online table 10.15) This is a faster rate of increase than the projected population increase and so the average household size is expected to decrease from 2.3 in

\section{Figure 4.6 Projected increase ${ }^{1}$ in households between 2006 and 2026, by region}

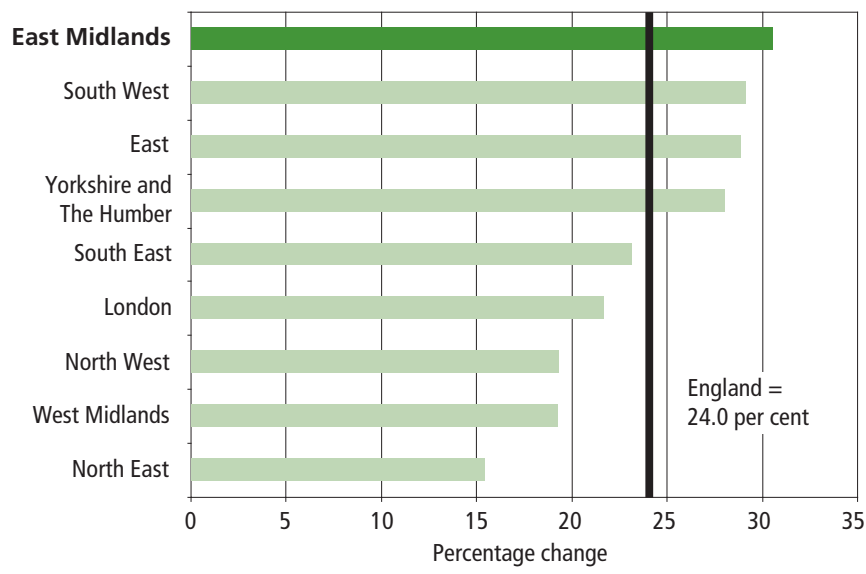

1 2006-based household projections.

Source: Communities and Local Government 
2006 to 2.2 in 2026, broadly in line with the average change in England. Over this time period all types of household in the region are expected to increase except married couple households (see Figure 4.7). The largest increase is projected to be in the number of one person households which is expected to increase by 50 per cent (from approximately 550,000 in 2006 to 827,000 in 2026).

Between 2002 and 2007 the stock of dwellings in the East Midlands increased by approximately 90,000, an increase of 5.0 per cent, one of the highest of any of the English regions and above the 4.0 per cent rise in the UK stock over the same time. By 2007 the East Midlands had a stock of 1.9 million dwellings, 7 per cent of the UK stock. (Online table 7.1)

Figure 4.8 shows the percentage of housing completions by tenure for each region. The majority of completions are for the private sector in all regions. In the East Midlands, 7 per cent of housing completions in 2006/07 were for registered social landlords, below the UK average of 12 per cent.

The Land Registry average dwelling prices in the region are consistently around 80 per cent of the average for England and Wales. This conceals wide variation at local authority level with dwelling prices in Ashfield and Mansfield consistently being around 75 per cent of the regional average. In comparison, prices in areas such as Rutland and the Derbyshire Dales are around 50 per cent above the average. (Online table 7.4)

\section{Education and training}

Educational achievement by pupils in the East Midlands is relatively low. In 2007/08, 63.0 per cent of pupils at the end of Key Stage 4 in maintained schools achieved five $A^{*}-C$ grades at
Figure 4.7 Household projections ${ }^{1}$ by household type, East Midlands, 2001 to 2026

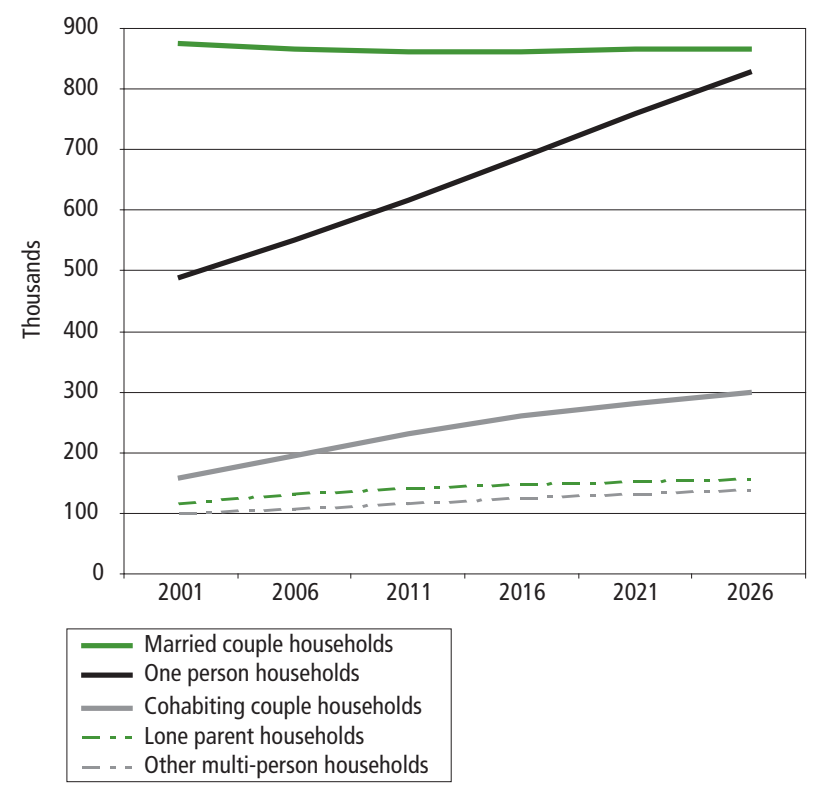

1 Projections are 2006-based.

Source: Communities and Local Government

GCSE level compared with 64.5 per cent in England. Although there had been some improvement between 2004/05 and 2007/08, the East Midlands still had the second lowest level of achievement of any region in 2007/08. (Online table 4.8).

In 2007 just over 13 per cent of the usual resident population aged 19 to 59/64 had no qualifications. Around 20 per cent had level 2 qualifications only and a similar percentage had

Figure 4.8 Housebuilding: completions by tenure, by region and country, 2006/07

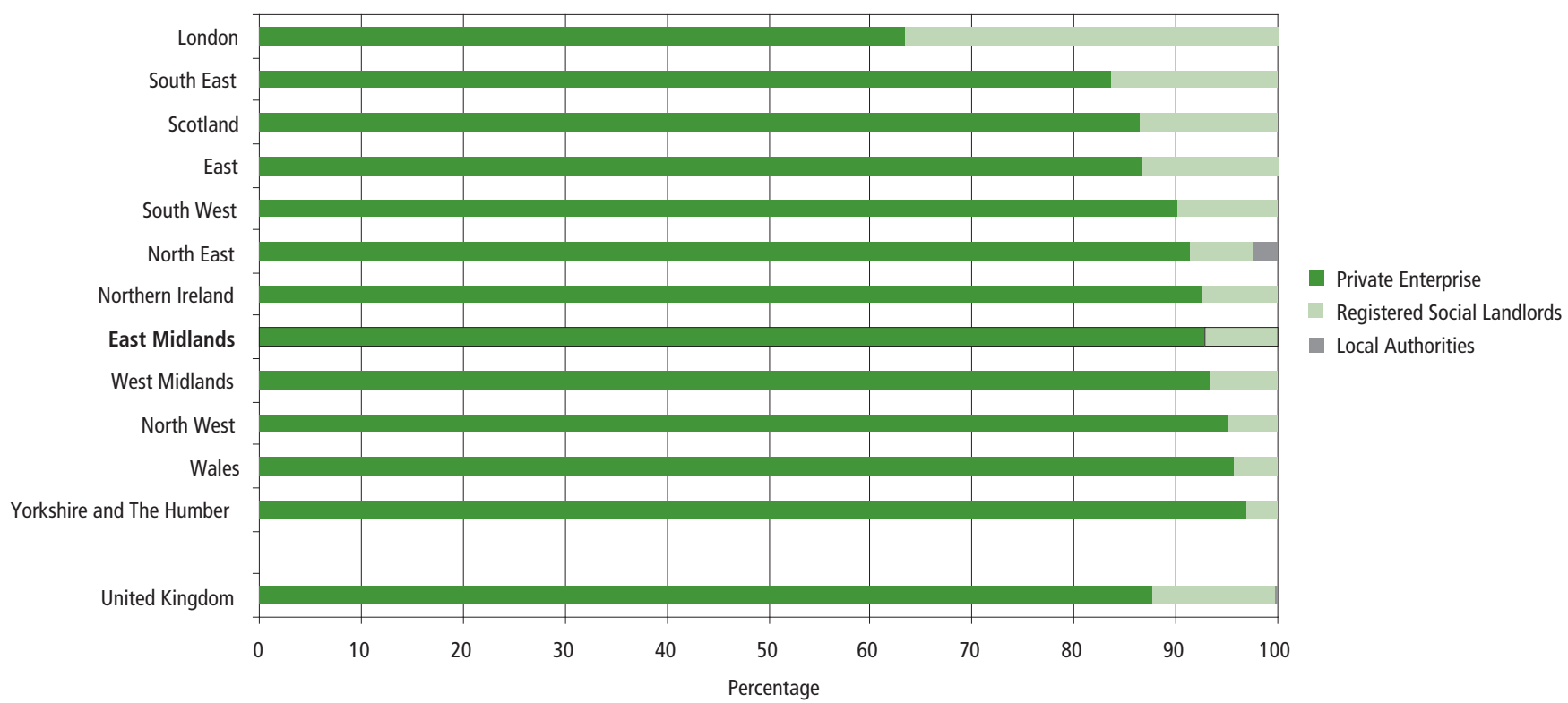

Source: Communities and Local Government; Welsh Assembly Government; Scottish Government; Department for Social Development, Northern Ireland 
Figure 4.9 Resident population aged

19-59/64 with qualifications below level 2', by region, 2007

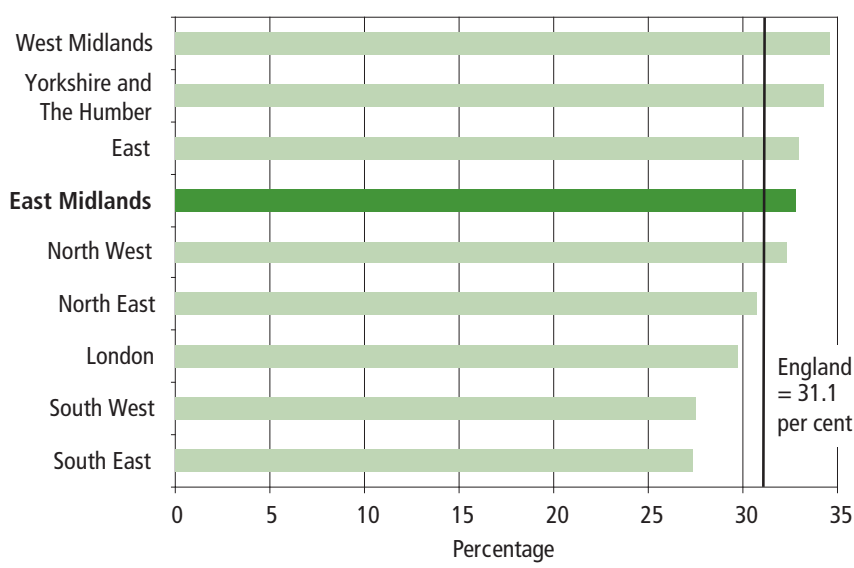

1 No qualification or qualification below level 2. (See Glossary) Source: Annual Population Survey, Office for National Statistics

level 3 only. All these were slightly more than the average for England. Figure 4.9 shows the proportion with no qualifications or level 2 qualifications for the regions of England.

At the other extreme, about 27 per cent of the region's residents aged 19 to state pension age had level 4 or higher qualifications, nearly 3 percentage points below the average for England and well below the percentages for London, the South East and the South West.

Within the economically active, the older age group are much more likely to have no qualifications. In the East Midlands nearly 16 per cent of economically active residents aged between 50 and state pension age had no qualifications compared with about 9 per cent of those aged 16 to 24 , and 8 per cent of those aged 25 to 49. These percentages were slightly higher than in England as a whole (Figure 4.10).

\section{Figure 4.10 Proportions of economically active residents with no qualifications: by age, 2007}

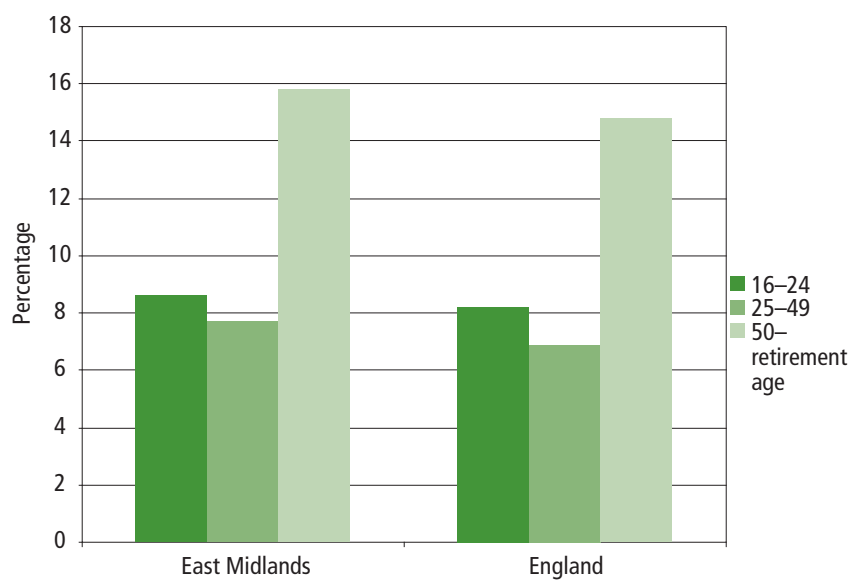

Source: Annual Population Survey, Office for National Statistics

\section{Figure 4.11 Percentage of establishments with skills gaps, by region, 2005 and 2007}

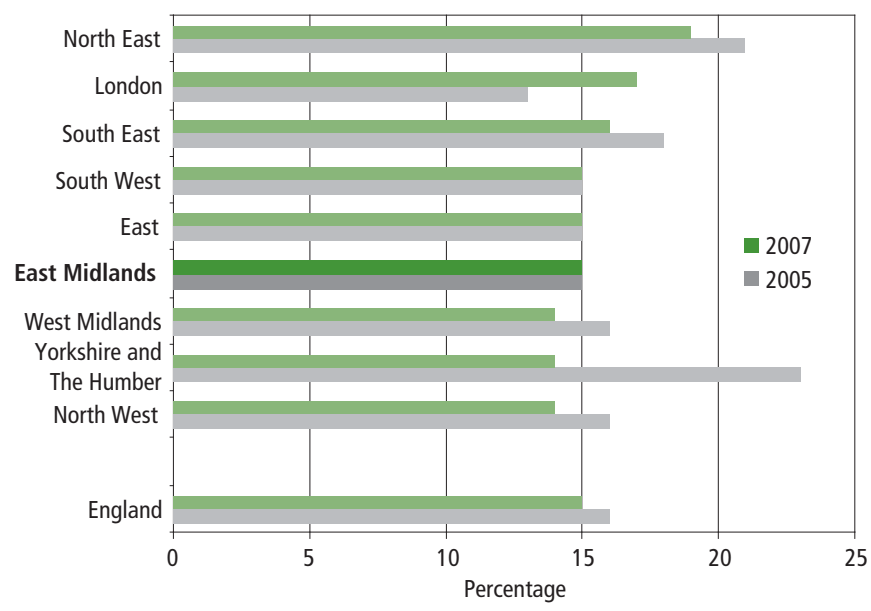

Source: National Employers Skills Survey 2007, Learning and Skills Council

In spite of the lower level of qualifications of the working age population, respondents to the National Employers Skills Survey undertaken in 2007 (not National Statistics) do not identify high rates of skills gaps when compared to other regions. In most regions about 15 per cent of establishments reported skills gaps, although the North East and London had higher rates (see Figure 4.11). The low levels of qualifications are therefore likely to reflect the skills requirements of the employers in the region. The next section includes a discussion of occupation levels of the resident population which supports the concept of relatively low skill requirements in the region.

\section{Labour market}

The employment rate in the East Midlands is above the average for the UK and has remained so for a long time. In October to December 2008, the seasonally adjusted employment rate was 76.2 per cent compared with 74.3 per cent for England: only the East of England, the South East and the South West regions had higher rates (see Figure 4.12).

The seasonally adjusted unemployment rate in October to December 2008 was 6.1 per cent, compared with 6.3 per cent in the UK; only the East of England, the South East and South West had lower rates in England. (Online table 9.10) However, unemployment is much higher in some local areas. For example, in the year ending March 2008, the modelled unemployment rates (see Glossary) varied from 2.6 per cent in the South Northamptonshire District Council area, to 9.9 per cent in Leicester UA, compared with the regional average of 5.2 per cent. (Online table 9.18)

The seasonally adjusted claimant count rate in the East Midlands in January 2009 was 4.0 per cent, above the UK average of 3.8 per cent. The claimant count rate in the region closely follows the pattern of increase in the UK during the 
Figure 4.12 Employment rate, by region, October to December 2008, seasonally adjusted

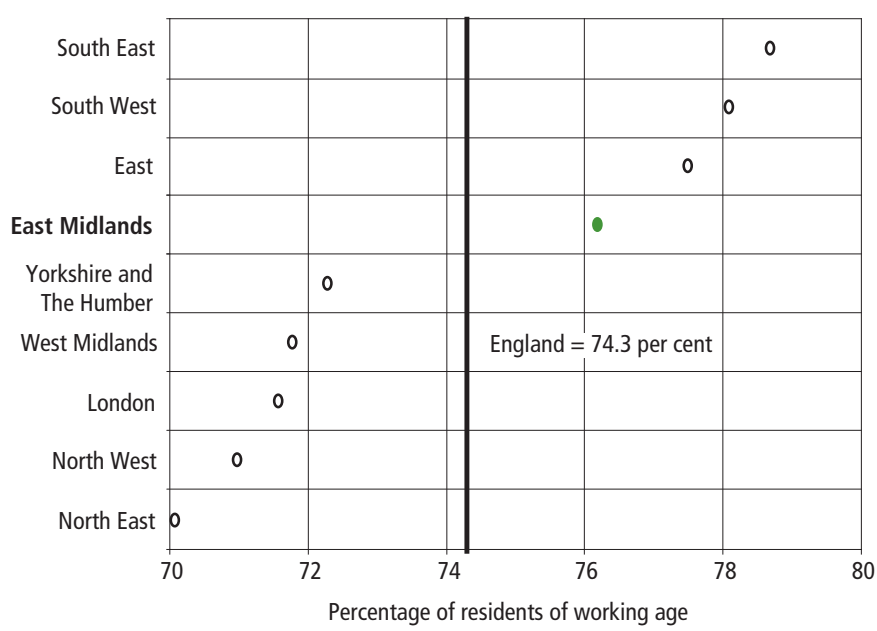

Source: Labour Force Survey, Office for National Statistics

recent worsening economic conditions, indicating that while the economic downturn is affecting the region, the economy is maintaining its position relative to other regions.

The economically inactive consist of those people who are out of work and are either not seeking work or are unavailable to start work. Economically inactive people have the potential to move into the workforce at some time in the future. The reasons for, and level of, economic inactivity in the working- age population of the East Midlands are similar to those for the UK working-age population as a whole. The three main reasons are 'looking after family or home', 'long term sick', or 'being a student' (see Figure 4.13).

In 2008, roughly equal numbers of people were in each of these three groups in the East Midlands. Between 1992 and 2004 there was a considerable reduction in the percentage of residents who were economically inactive because they were looking after their family or home. Over this time period, the largest increase in reasons given for inactivity was 'long term sick'. The percentage of residents who were students also increased between 1992 and 2004. However between 2005 and 2008 there was very little change in the proportions.

The economically inactive group can be divided into those who want a job and those who do not. While this is not an exact reflection of whether people will move into economic activity in the near future, it does give some indication of the strength of people's labour market attachment. In 2008 over 76 per cent of the economically inactive in the East Midlands wanted a job, one of the highest rates of any of the regions.

Average (median) weekly earnings (see Glossary) of full time employees in the East Midlands was $£ 450$ in April 2008, below the UK average of $\_479$ but very similar to most other regions outside the south east corner of Britain. Men working in the region earn on average $\mathrm{f} 114$ more in full time earnings than women which is slightly above the UK average difference of f109. (Figure 4.14 and Online table 9.19)

\section{Figure 4.13 Reasons for economic inactivity', East Midlands, 1992 to $2008^{2}$}

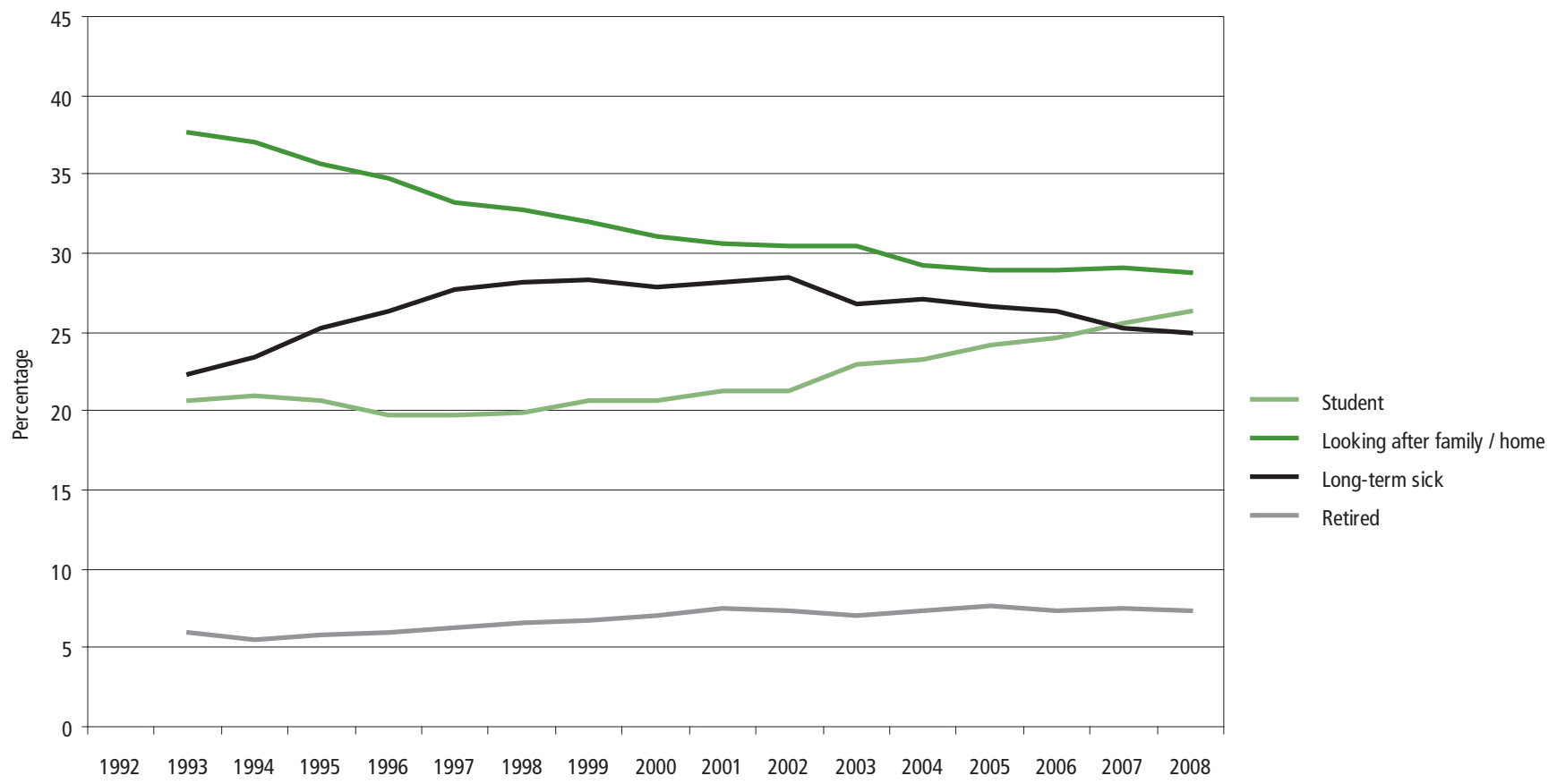

1 As a percentage of inactive working age residents.

2 Second quarter of each year. 
Figure 4.14 Median gross weekly pay for residents and in the workplace, by region and country, April 2008 range from 30 per cent of employed residents in Leicester to 48 per cent in Rutland. However, the comparison of the earnings of residents with those of employees working in the region suggests that some of the highest paid residents - many of whom will be in highly skilled occupations - have jobs outside the region.

\section{Economy and industry}

\section{Box 1 Measuring Regional Economic Performance}

When measuring the economic performance of regions or sub-regions, the following should be considered:

Gross Value Added (GVA) is a good measure of the economic output of a region.

GVA per head, which divides output of those working in a region by everybody living in the region, should not be used as an indicator of either regional productivity or income of residents.

GVA per hour worked and GVA per filled job are the preferred measures of productivity of an area

Gross Disposable Household Income (GDHI) per head is a good indicator of the welfare of residents living in a region.

Productivity, Income and Labour Market indicators should be used together to provide a more complete picture of regional and sub-regional economic performance.

For further information, see the National Statistician's article 'Measuring regional economic performance' which can be found at www.statistics.gov.uk/cci/article.asp?ID =2103

In 2007 the East Midlands economy generated $f 77.9$ billion of Gross Value Added (GVA) which was 6.4 per cent of the UK total. The GVA per head of $£ 17,700$ per resident was over 10 per cent below the UK average. Compared with 2006 there was an increase in total GVA of 5.9 per cent, a 5.0 per cent increase in GVA per head, a slight decrease relative to the UK average. Since 1997 there has been a divergence between London as the leading region and regions at the lower end, such as East Midlands, although the region is by no means the lowest. GVA per head in the East Midlands was 93 per cent of the UK value in 1997 and less than 89 per cent by 2007.

(Online table 3.1)

In 2007 labour productivity (GVA per hour worked) in the East Midlands was 92.3 per cent of the UK average, lower than the East of England, London, the South East and the South West, but similar to all other English regions (see Figure 4.15 and Online table 3.3)

The relative industrial distribution of GVA differed between the regions. In 2006, 19 per cent of GVA in the East Midlands 
Figure 4.15 Labour productivity: gross value added per hour worked, by region, 2007 (UK=100)

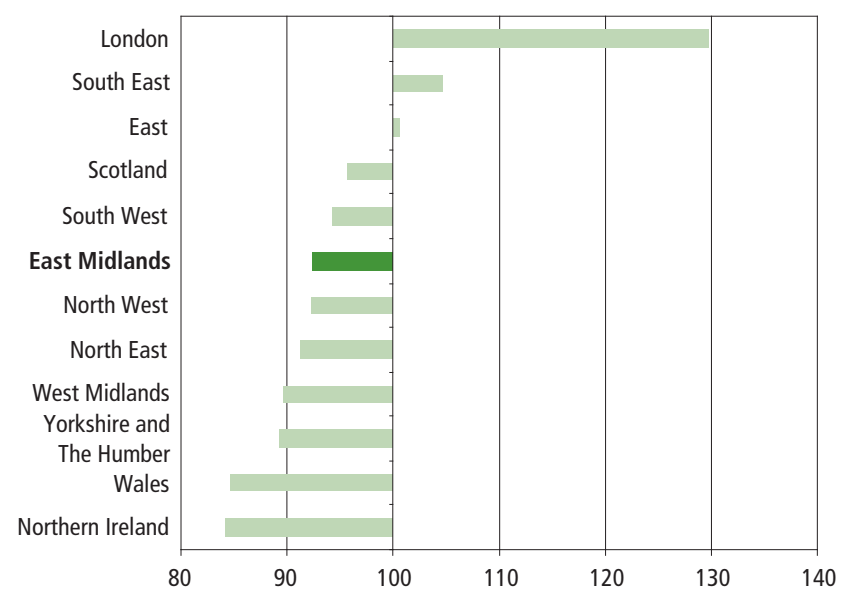

Source: Office for National Statistics

was from manufacturing, more than the UK average of 13 per cent and the highest percentage contribution of manufacturing to GVA of any of the UK countries and English regions. The largest percentage contribution to GVA in the East Midlands was from 'Real estate' (20 per cent) and this has been the sector with the largest growth over the last ten years. However the service industry groups combined contributed less than 70 per cent of headline GVA in 2006, the lowest percentage for any of the regions and countries in the UK and well below the average for the UK as a whole. (Online table 3.2)

The region is one of the smaller English regions in terms of its share of jobs, with 6.8 per cent of all UK employee jobs in 2007 and 7.0 per cent in 1997, indicating that the workforce in the East Midlands has grown at a slightly lower rate than the UK. The industrial employment pattern in the East Midlands in June 2008 shows that manufacturing made up 15 per cent of employee jobs, compared with the UK average of 11 per cent. This is the largest percentage for any region or country in the UK. Employment in finance, property and business services was 17 per cent of jobs, below the UK average of 22 per cent and one of the smallest percentages in any English region.(Online table 9.4)

Business expenditure on Research and Development in the East Midlands was $f 1,053$ million in 2007, 6.5 per cent of the UK total. The expenditure was 1.3 per cent of the GVA in the region, very similar to the North West and the South West and slightly above the UK average (see Figure 4.16 and Online table 3.19).

\section{Disadvantage}

The Index of Multiple Deprivation 2007 shows the variation between the regions in overall levels of deprivation (Figure 4.17). The East Midlands had less of the most deprived Lower

\section{Figure 4.16 Business enterprise research and development expenditure as a proportion of gross value added, by region, 2007}

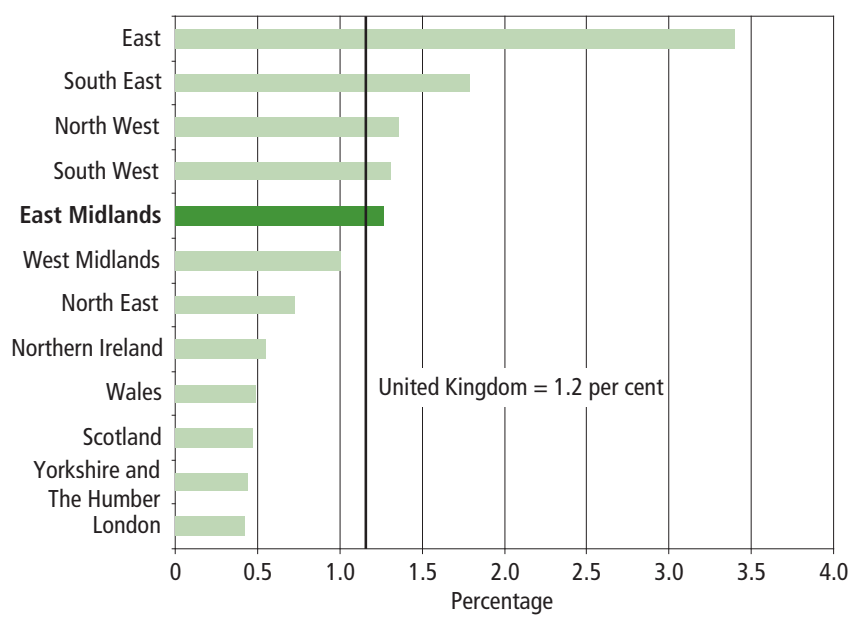

Source: Office for National Statistics

Layer Super Output Areas (LSOAs) in England than all regions apart from the East of England, the South East and the South West. However this masks considerable variation across the region. Figure 4.18 has a similar analysis by upper tier authority in the East Midlands. Rutland had no LSOAs in the most deprived 20 per cent in England while the shire counties had very low proportions. However, 60 per cent LSOAs in Nottingham UA and over 45 per cent of LSOAs in Leicester UA were at this level of deprivation.

When the percentage of the working age population claiming either incapacity or work-related benefit is used as an indicator of work deprivation, the sub regional pattern is similar to that shown in Figure 4.18. The time series of these data show the persistent work deprivation of residents in some of these authorities. Of the nine upper tier authorities the rates of benefits vary from just over 4 per cent in Rutland UA to over 16 per cent in Nottingham UA in February 2008. In spite of improvements in the absolute rates, all nine authorities have the same relative positions within the region in 2008 as they did in 2000 .

\section{Health}

Life expectancy at birth for both male (77.6 years) and female (81.6 years) residents in the East Midlands in 2005 to 2007 was similar to England (77.5 and 81.7 respectively). Figure 4.19 shows the differences between life expectancy at birth in each of the counties and unitary authorities and the average for the East Midlands region. Males born in Nottingham UA could expect to live 3.0 years less than the regional average, while those born in Rutland UA could expect to live 2.5 years longer. For females born in Leicester the expectation of life was 1.7 years less than the regional average while for those born in Rutland UA life expectancy was 3.1 years longer than the regional average. 
Figure 4.17 Distribution of LSOA' rankings on the 2007 Index of Multiple Deprivation, by region

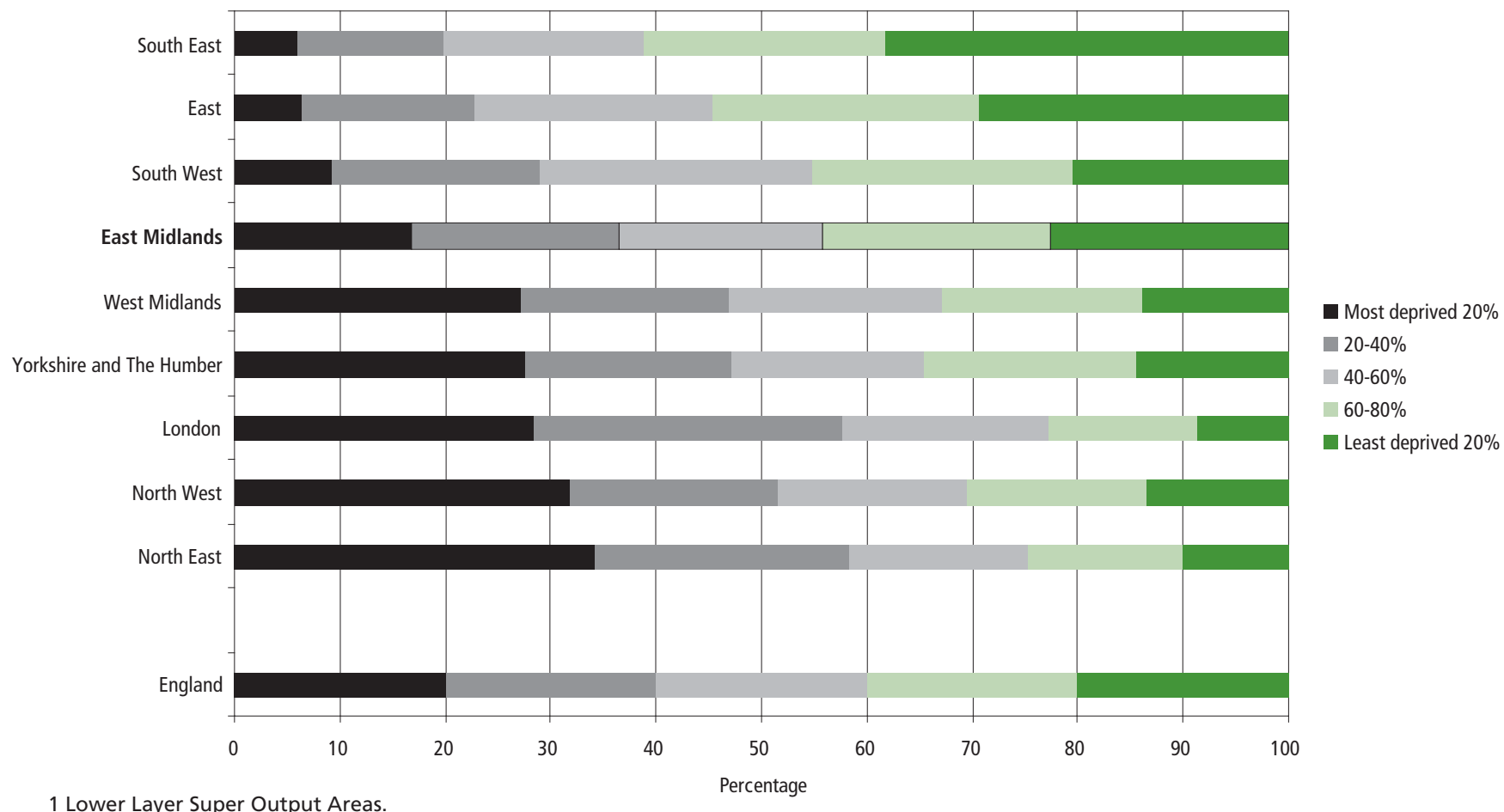

1 Lower Layer Super Output Areas.

Source: Communities and Local Government

\section{Box 2 Index of Multiple Deprivation 2007}

The Index of Multiple Deprivation (IMD) provides a summary measure of relative deprivation at Lower-layer Super Output Area (LSOA) level in England. The IMD aims to provide a nationally consistent measure of how deprived an area is by identifying the degree to which people are disadvantaged by factors such as low income, unemployment, lack of education, poor health, and crime. Particular points to note:

- not all deprived people live in deprived areas and conversely, not everyone living in a deprived area is deprived; the indicators identify areas with characteristics associated with deprivation - not deprived people.

- the indices should not be used as a measure of affluence. A lack of income deprivation does not necessarily equate to affluence
The indices provide a relative measure of deprivation and therefore cannot be used to determine how much more deprived one LSOA is than another.

This article uses the rankings of all LSOAs in England, which have been divided into five equal sized groups, or quintiles. In England 20 per cent of LSOAs are in the most deprived quintile and 20 per cent in the least deprived quintile and so on. If an area (region or local authority) had the average distribution of deprivation they would have 20 per cent of LSOAs in each quintile.

For more information on the IMD see article on page 93 and the Communities and Local Government website: www.communities.gov.uk/indices
The East Midlands had similar age-standardised mortality rates to England for cancer and circulatory disease in 2005 to 2007. The rate for respiratory disease, however, was significantly lower than that for England. The regional rates mask considerable variation between the upper tier authorities as shown in Figure 4.20 where the mortality rates for circulatory disease, cancer and respiratory disease are indexed to England $=100$. For circulatory disease, Nottingham UA, Derby UA,
Leicester UA and Derbyshire have rates above the English average while the rates for Rutland UA, Leicestershire, Northamptonshire and Nottinghamshire are below the England average.

For respiratory disease the sub-regional variation is even more pronounced, with Nottingham UA and Leicester UA considerably above the England average and Rutland UA, Leicestershire and Lincolnshire considerably below. There is less 
Figure 4.18 Distribution of LSOA' rankings on the 2007 Index of Multiple Deprivation, for local authorities in the East Midlands

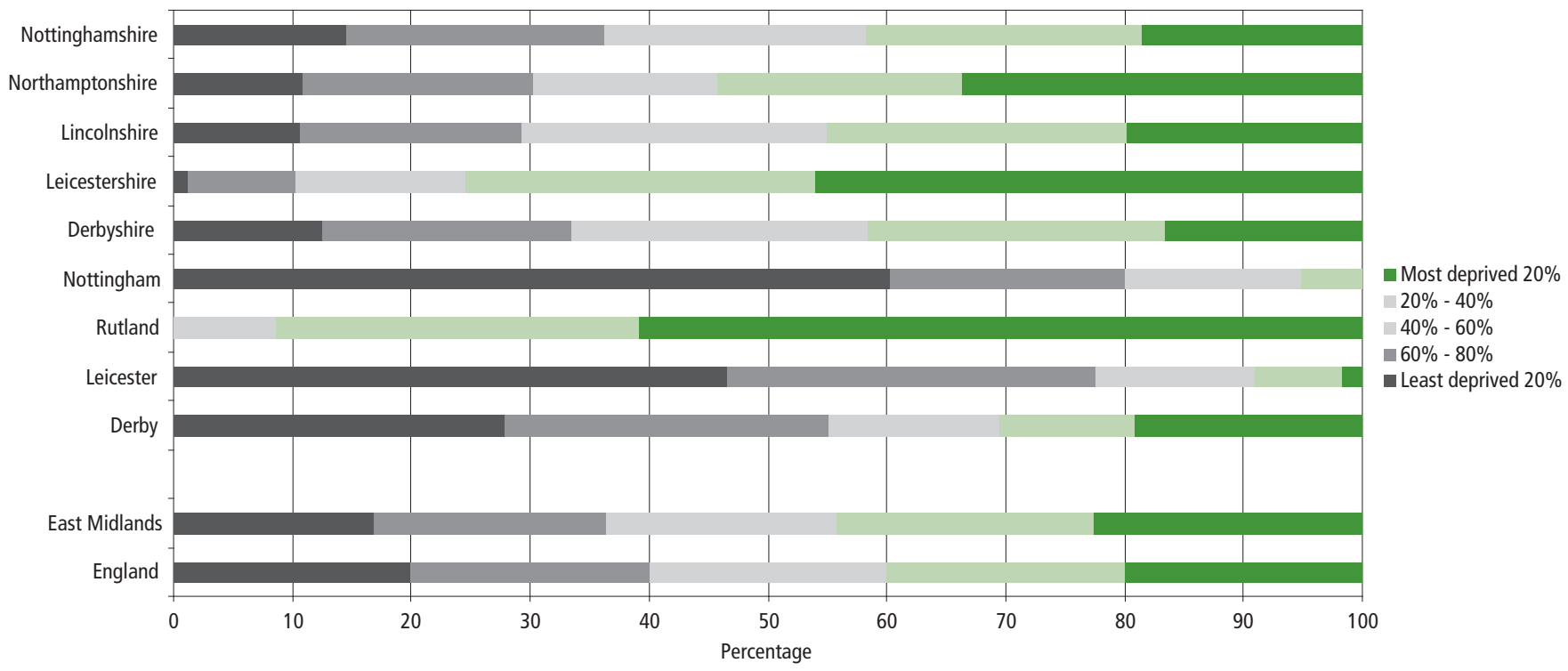

1 Lower Layer Super Output Areas.

Source: Communities and Local Government

Figure 4.19 Difference in life expectancy at birth between the counties and unitary authorities and the average for the East Midlands, 2005 to 2007

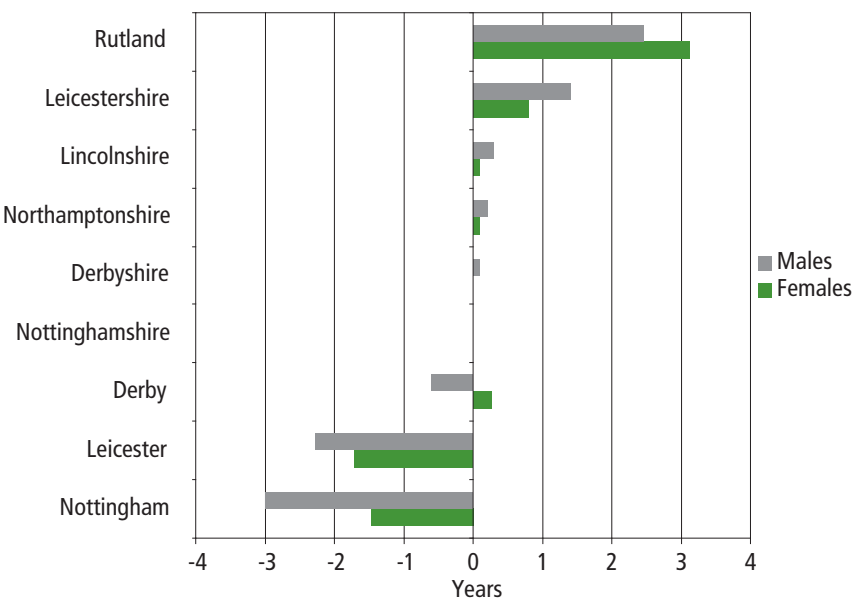

Source: Office for National Statistics

sub-regional variation in the cancer mortality rate with six of the nine authorities having similar rates to the England average. The exceptions are Nottingham UA which has a cancer mortality rate considerably above the England average and Leicestershire CC and Rutland UA where the cancer mortality rates are considerably below.

\section{Transport}

The average distance travelled per person per year in the East Midlands by all modes of transport during 2005-06 was 7,140 miles (or 27 miles per weekday) which was similar to the Great Britain average. Average mileage in cars and other private road vehicles amounted to 6,140 miles, or 86 per cent of travel by all modes, with the rest mainly rail (380 miles), bus (230 miles) or walking (210 miles). (Online table 11.4)

With three quarters of commuters travelling to work by car, van, minibus or works van in 2007, the East Midlands had one of the three highest levels among the English regions. This was the same as the South West and slightly lower than the West Midlands. (see Figure 4.21 and Online table 11.7)

\section{Environment}

National Parks amount to 890 square $\mathrm{km}$ of land in the East Midlands, 6 per cent of the region's area, compared with a UK average of 8 per cent. In total, 4 per cent of national park land in the UK is in the East Midlands. Land within an Area of Outstanding Natural Beauty amounts to 3 per cent, compared with 13 per cent for the UK. (Online table 5.8)

The East Midlands had the third highest rate of $\mathrm{CO}_{2}$ emissions for any region in both 2005 and 2006. In both years the North East and Yorkshire and The Humber had higher per capita rates. Most regions had shown no improvement between these two years. (See Map 9.9 on page 152)

The region had the third highest rate of recycling of household waste in 2006/07, only the East of England and the South West had higher rates. Between 2002/03 and 2006/07 recycling rates for household waste improved at a faster rate in the East Midlands than the average for England. In 2002/03 the recycling rate was average, but by 2006/07 the rate was 4 per cent above average at 35 per cent (see Figure 4.22 and Online table 5.12). 
Figure 4.20 Mortality rates for selected diseases, 2005 to 2007 (England = 100)

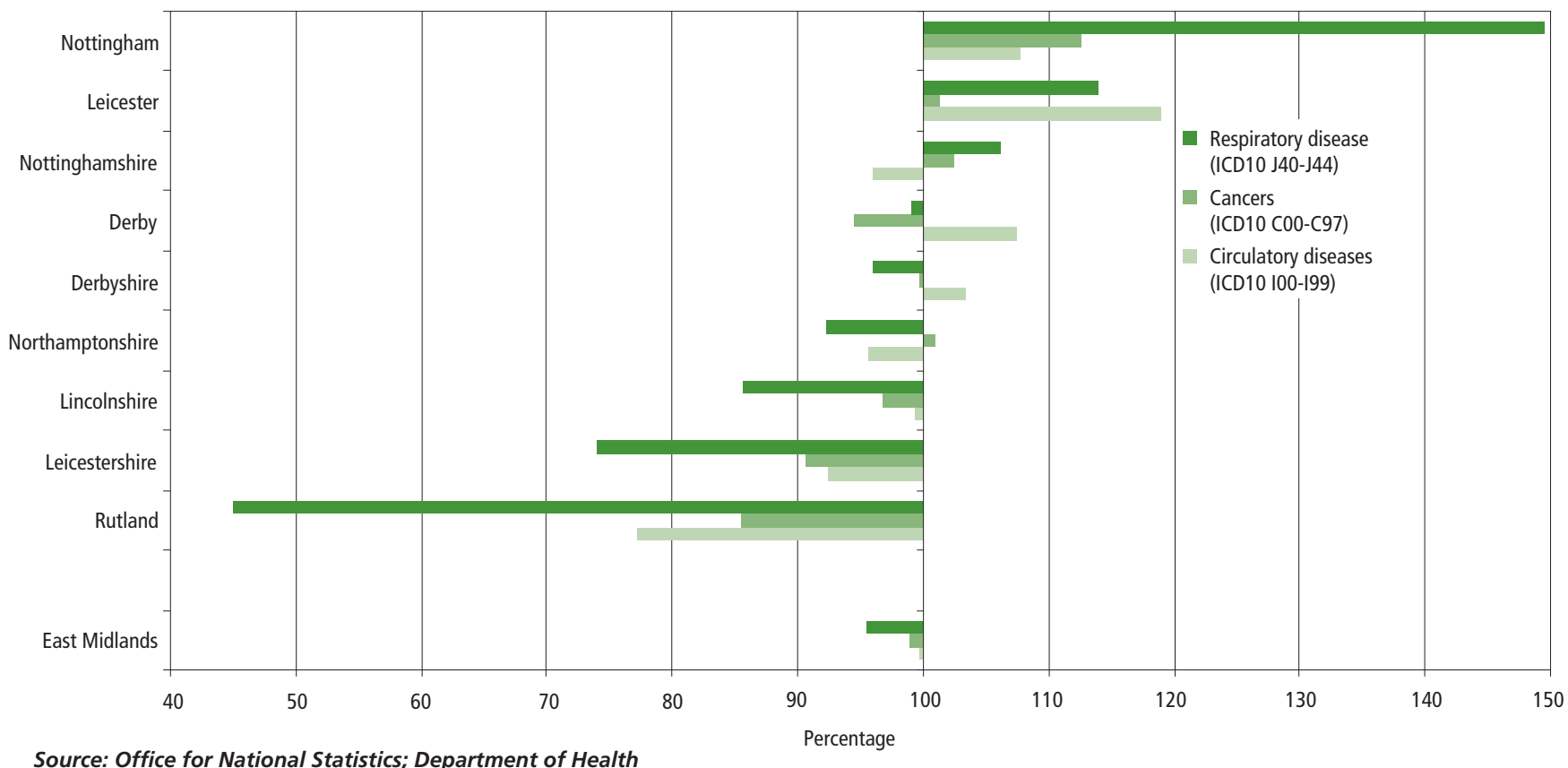

Figure 4.21 Usual method of travel to work by region of residence, fourth quarter 2007

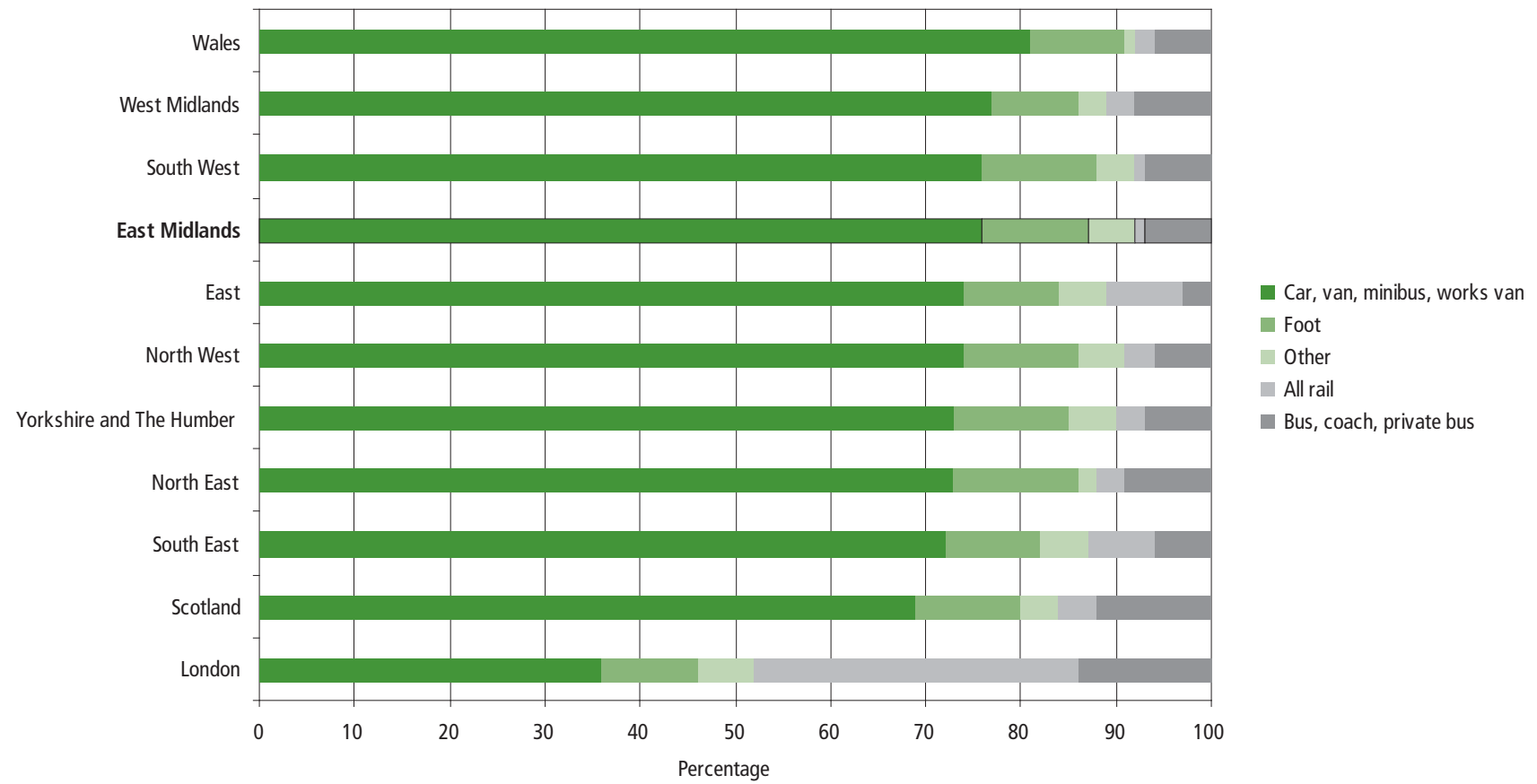


Figure 4.22 Percentage of household waste recycled and composted for selected regions, 2002/03 to 2006/07

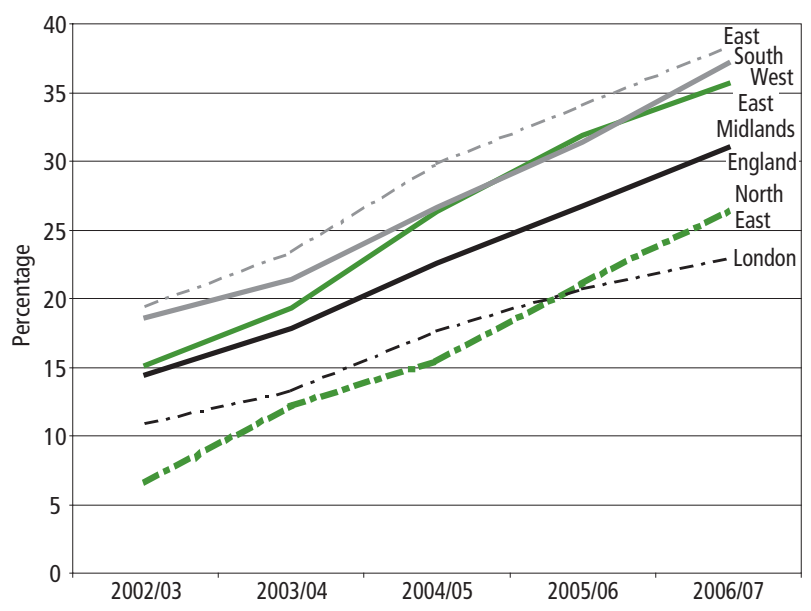

Source: Department for Environment, Food and Rural Affairs

\section{Crime and justice}

On average, the East Midlands has crime rates similar to the English average; for example, there were 1,730 recorded offences of violence against the person for each 100,000 residents in 2007/08 compared with an English average of 1,760 (Online table 2.3). However, the regional average masks considerable sub-regional variation. For example, the rates of violence against the person in the upper tier authorities ranged from 680 per 100,000 residents in Rutland UA to 3,440 per 100,000 residents in Leicester UA.

In 2007 , over 100,000 people aged 18 or over, were found guilty of offences and sentenced, at a rate of 29 sentences per 1,000 residents which is slightly over the average for England. (Online table 2.10)

\section{$a$

\section{Related titles from the}

\section{Office for National Statistics}

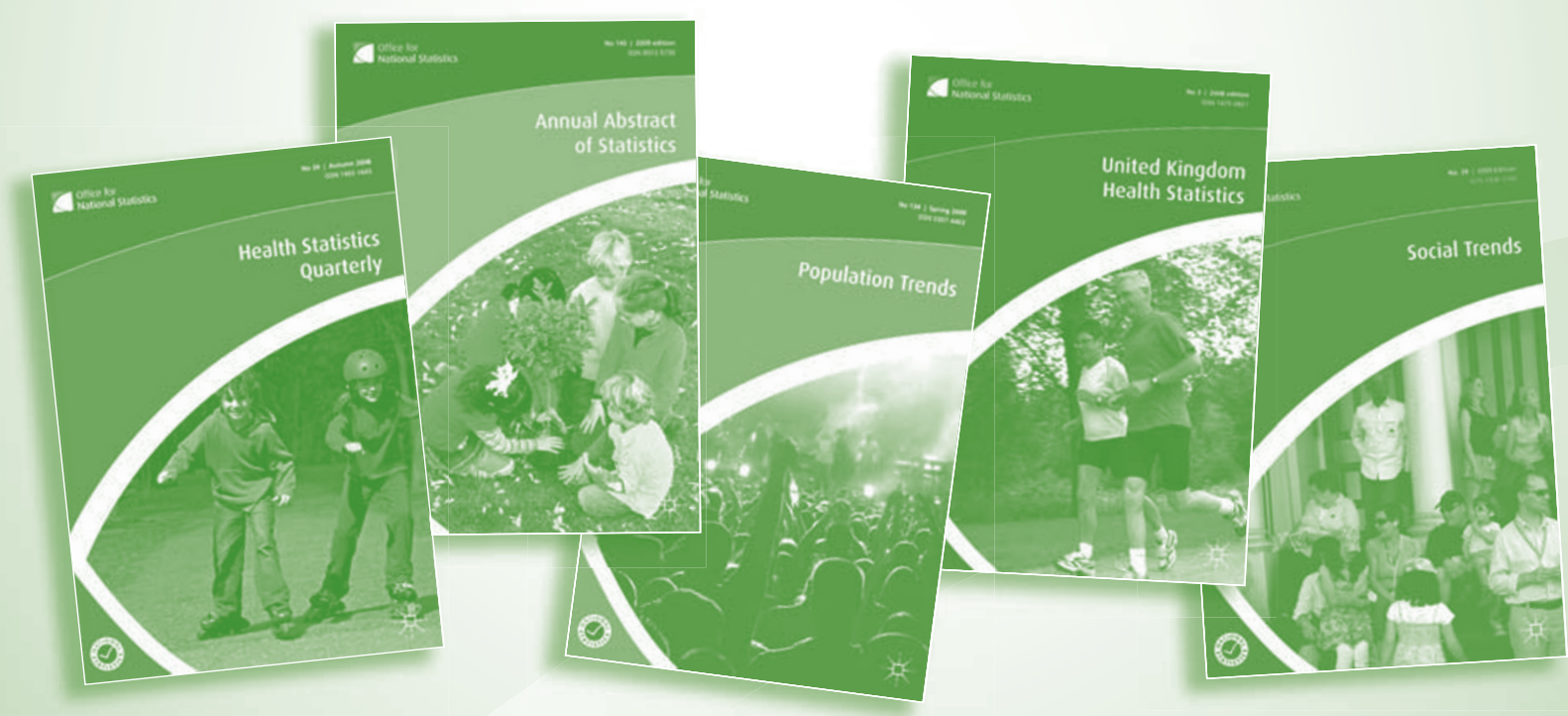

www.palgrave.com/ons/ 